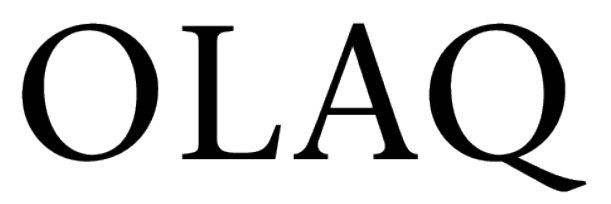

Volume 21 , Number 2 Oregon Libraries: Ideas at Work| Pages 17 - 24

9-9-2015

\title{
What's Old is New Again: The Popular Reading Collection at University of Oregon Libraries
}

Lydia Harlan

University of Oregon Library

Miriam Rigby

University of Oregon Library

Follow this and additional works at: http://commons.pacificu.edu/olaq

Part of the Library and Information Science Commons

Harlan, L., \& Rigby, M. (2015). What's Old is New Again: The Popular Reading Collection at University of Oregon Libraries. OLA Quarterly, 21(2), 17-24. http://dx.doi.org/10.7710/1093-7374.1798

(C) 2015 by the author(s).

OLA Quarterly is an official publication of the Oregon Library Association | ISSN 1093-7374 | http://commons.pacificu.edu/olaq 


\section{What's Old Is New Again: The Popular Reading Collection at University of Oregon Libraries}

\section{by Lydia Harlan, MLIS}

Acquisitions Receiving Specialist University of Oregon Libraries lharlan@uoregon.edu

and

\section{Miriam Rigby}

Social Sciences Librarian University of Oregon Libraries rigby@uoregon.edu

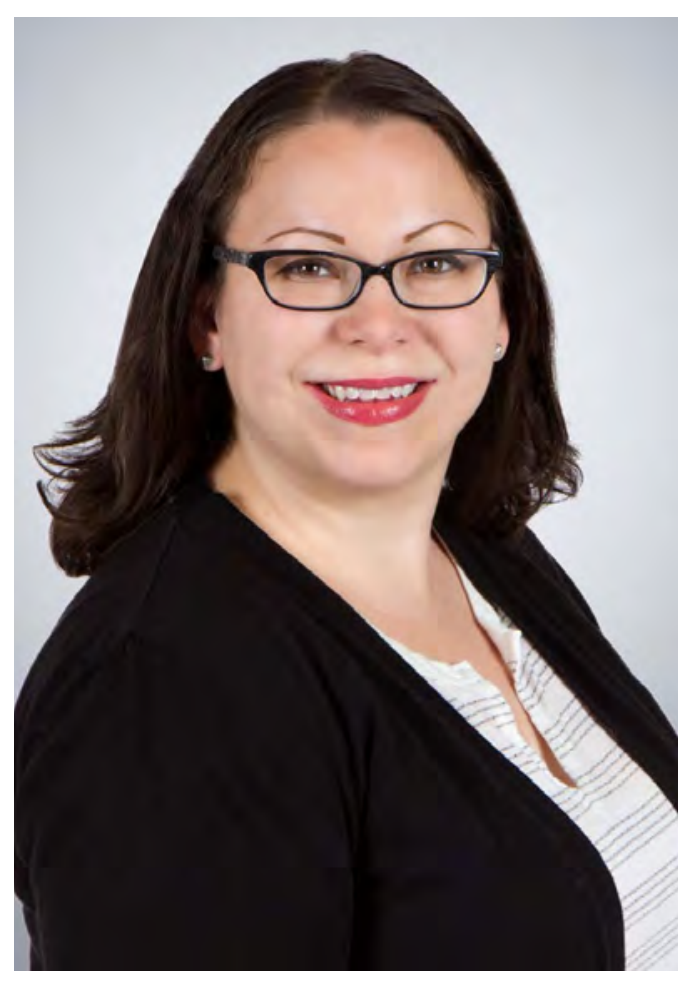

LYDia HARLAN

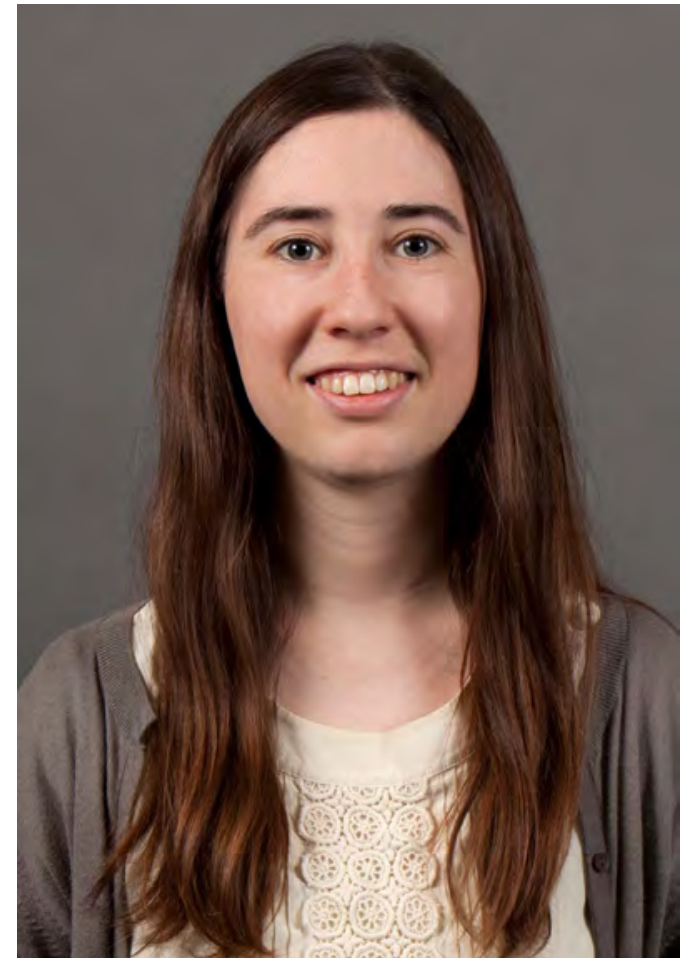

Miriam RibGy
University students, staff, and faculty read for fun and want their campus library to support this pursuit. We have the direct requests and circulation statistics to prove it. University of Oregon students expressed interest in the development of a Popular Reading Collection (PRC) at UO Libraries during a regular meeting of the Dean's Student Advisory Group in February 2011. Former Dean Deborah Carver brought the idea to Collection Managers, our collection development team, who subsequently undertook an investigation of how we might pursue and support this request. Now, more than four years later, we have a lively redesigned space and have honed our methods of building and circulating the collection. Our circulation stats show that our academic community is indeed using the PRC and is checking out more material as we revise the program. With this success, it's time to reflect on our implementation of the PRC and what we've learned.

\section{Supportive Research, Community and Strategic Alignment}

The concept of a PRC was not a new or original idea. Browsing Rooms were once common in academic libraries, but over the decades, students were increasingly directed to the public library for any non-academic interest. Julie Elliott writes, "Part of what may have led to the decline in students' extracurricular reading is an attitude of elitism and even hints of censorship in the name of selection on the part of the librarians recommending the books," (2007, p. 35). Yet, the (re)implementation of a PRC is a newer, revitalized idea based on recent 
studies. Pleasure reading benefits the student in a number of ways, from nurturing creativity (Kelley \& Kneipp, 2009), to enhancing empathy (Djikic, Oatley, Zoeterman, \& Peterson, 2009; Kidd \& Castano, 2013). J.D. Gallik found that "a significant connection was found between achievement and the time these college students spent reading for pleasure ..." (1999, p. 480).

Furthermore, UO Libraries' branch locations had already embraced a variety of popular materials for recreation and research. Beyond the more standard music and film collections, in 2007, Singer Science Librarian Annie Zeidman-Karpinski spearheaded a video game collection at UO's Allan Price Science Commons \& Research Library for recreational and curricular use, complete with collection development policy. And more recently, Yen Tran, Outreach \& Student Engagement Librarian at the Global Scholars Hall Library Commons, has cultivated a collection that includes foreign language popular magazines and other light reading aimed at students studying the world's languages and cultures. Popular reading is once again finding a place in the academic library, but we had to determine whether it was the right fit for the UO Libraries' main branch, the Knight Library.

With student endorsement, clear precedent on campus, and research supporting a new PRC, we studied how it aligned with the library's strategic initiatives. As the initial $2011 \mathrm{re}-$ quest came through the Dean's Student Advisory Group, there was positive alignment with the initiative "Improve the User Experience" (UO Libraries Strategic Directions, 2012). The character of the collection was also planned to harmonize with the initiative to advance diversity through the purposeful selection of items featuring characters who are people of color, have disabilities, are LGBTQ, and are from other diverse backgrounds, including international locations and viewpoints. Likewise, items would be selected to represent diverse authors. With the conceptualization of the collection in support of these initiatives, we turned to space. Spurred by the concept that this is not just a collection of books, but an experience designed to create a culture of reading at the University of Oregon, fresh carpeting and painting were prioritized for the South Reading Room of the Knight Library where the PRC is housed. Tens of thousands of dollars would be invested in soft seating and specialized, distinctive shelving. This vision meshed well with the UO Libraries' Space Planning Team's goal "to create a more welcoming, comfortable and effective environment for library users and staff."

\section{Implementation of the First Iteration}

Our plan for the collection was approved and ready for implementation. In late 2011 the first iteration of our PRC began, led by collection managers Cara List and Miriam Rigby, with a few additional team members from relevant library departments. After investigating various methods for providing popular reading material, including e-books, lending pre-loaded e-reader devices, and print book options, the library signed an agreement with McNaughton Library Subscription Services to lease print adult and young-adult fiction, for an annual fee. In addition to determining that we wanted to focus on physical books, the major features that attracted us to McNaughton's service included that the books arrived 
shelf-ready, their selection tool was relatively easy to use and provided useful information about the content and age level of the books, and they provided monthly lists of soon-tobe-published titles to aid in the selection of items. A further perk was that in leasing books, we did not have to worry about if a particular title perfectly fit our collection development goals as we could easily rid ourselves of it if there were no interest in it. In the beginning it was exciting and easy to select materials, but as time went on, challenges arose.

First, we had a hard time keeping track of the pricing structure. The leasing program allowed for points to be applied to titles, so some titles were one point and some were two, and we found it difficult to discern which were which. After a couple of months in the program we discovered there was an additional fee attached to each title ordered, for cataloging and processing. It's not clear where the breakdown in communication occurred, but the consequence was indeed clear. Our funding was structured for one annual payment, not an annual payment plus variable additional monthly costs, so this led to confusion, crisis management, and ultimately, occasional invoices for twenty-five cents.

Another challenge became visible when circulation statistics came in. We saw that items from certain series were checked out frequently, and because they were popular, we wanted to collect the complete series. However, because the leasing program focuses on very recent titles, older titles in a series were often unavailable. We investigated purchasing the older series titles separately, but decided against having a mix of leased and purchased items in the same collection because it would have added an overwhelming level of complexity to what was supposed to be a relatively small, easy, fun collection.

Lastly, we under-anticipated the amount of time it would take to deselect materials. With multiple people contributing to the selection process, there was no one clear person in charge of deselection. With so much time and energy spent getting books onto our shelves, we also did not have much time to spare to go through the full process of weeding out items, deaccessioning them, and sending them back to the warehouse. Further, due to our slow start in selecting titles and related issues with adding titles, we never managed to hit our full title capacity for our plan, so we were hesitant to have bare shelves. Nonetheless, it was clear that some titles were not circulating at all, so it was necessary to implement a weeding process.

After investing three years into this program, and sending back hundreds of books that had never circulated, it became clear that though interest in popular reading was still strong, something needed to change. A quick calculation proved that it would have been cheaper if we had simply purchased the titles we wanted at the inception of the program. This revelation came during a time of multiple large changes in the library, as one of the core collaborators on the project, Cara List, took a new opportunity with Northwestern University, and the UO Libraries was preparing for an integrated library system (ILS) migration. Rather than abandon the program altogether, the leadership was changed to facilitate a new methodology. Miriam Rigby contacted Lydia Harlan, the primary contact for the acquisitions department processes for the PRC, as she had expressed interest in finding a way to make the program better suited to our needs. Acquisitions was already facilitating the McNaughton leasing program, so we decided to do what acquisitions does best: buy books. 


\section{Developing the Process}

The McNaughton books would be returned, and the timing was auspicious. It was April of 2014 and we were migrating to a new ILS. We realized that if we didn't act immediately the McNaughton bibliographic data might be forever trapped in the oubliette of a system we didn't fully understand or know how to get data from. The new purchasing plan would go into effect in fiscal year 2014-2015 (FY14), and it takes time to order, receive, and process materials. Fearful that six months of empty shelves would be the death of the PRC, we needed a transition plan. During the cross-over period of 2014 approximately 900 popular fiction books were drawn from the general Knight Library collection and relocated to the PRC shelves promptly after the McNaughton leased materials were removed. Staff selected these books by hand, walking the stacks using a barcode wand to create a list of fiction titles with good-looking covers that would look enticing on our PRC shelves. This list was then passed along to Access Services, who batch-switched the locations, and had students pull the books and add small "Popular Reading" stickers above their call numbers so they could be shelved correctly without taking hard-to-reverse measures.

During the downtime when our ILS wasn't available due to migration, we took the time to design the next implementation of the PRC. The leased materials had come in library binding, and we decided that our homegrown collection would be made up of recently published paperbacks. They are less expensive per book, thus we could grow the collection faster and be less concerned about shrinkage leaving bare shelves. The slight publishing delay for paperbacks is more than made up for by these benefits.

One exception to the paperback guideline is graphic novels, as these are often not offered in paperback. Serendipitously, at the same time we were transitioning to this new iteration, we learned that UO would be offering a program in Comics and Cartoon Studies. Retired paperbacks will likely be recycled, however Collection Managers agreed our graphic novels could transfer to the general collection once their circulation within the PRC declined, so it would be worthwhile to invest in hardback editions. It should be noted that UO's John E. Jaqua Law Library has a similar, separately-managed Popular Reading Collection which they launched following the initial success of our PRC. Like us, they decided to purchase rather than go with a leasing program, however, unlike us, hardback was their preferred format.

Switching to a direct-purchase and in-house processing model produced the need for a number of new processes to serve and maintain this collection. We would need a tool for selection and a method for placing order requests with our Acquisitions unit. At first we considered Goodreads, but found it lacked reliable paperback publication dates, and instead, created Amazon Wish Lists. In addition to the notable retailer's obvious suitability for popular book searching, the lists can be sent to our Acquisitions unit to be placed as an official order. At this point the person ordering could choose to order through Amazon for maximum efficiency, but the recent volume of our orders has been so large that placing these orders on the website through the department procurement card (a.k.a. Visa credit card) would add unwanted complexity. Not having an annual prepayment to a leasing company affords us flexibility in adapting to budgetary ebbs and flows, so this may be 
a feature we would employ in the future. Our first round of orders was sent through the Pacific Northwest's favorite book seller, Powell's Books, in an effort to keep the business local. Recently, Acquisitions has been sending more business to Midwest Library Service for ease of billing.

\section{Assessment}

While we awaited our first wave of purchases we conducted an assessment that produced several interesting findings. A third of the temporary collection had a very low PRC to Knight (general collection) circulation ratio. That is to say the number of checkouts of a particular title in the general collection far exceeded the number of checkouts of that same title while it was temporarily relocated to the PRC. Many of these titles did not circulate in the PRC at all during the period of 5/2014 to 5/2015.

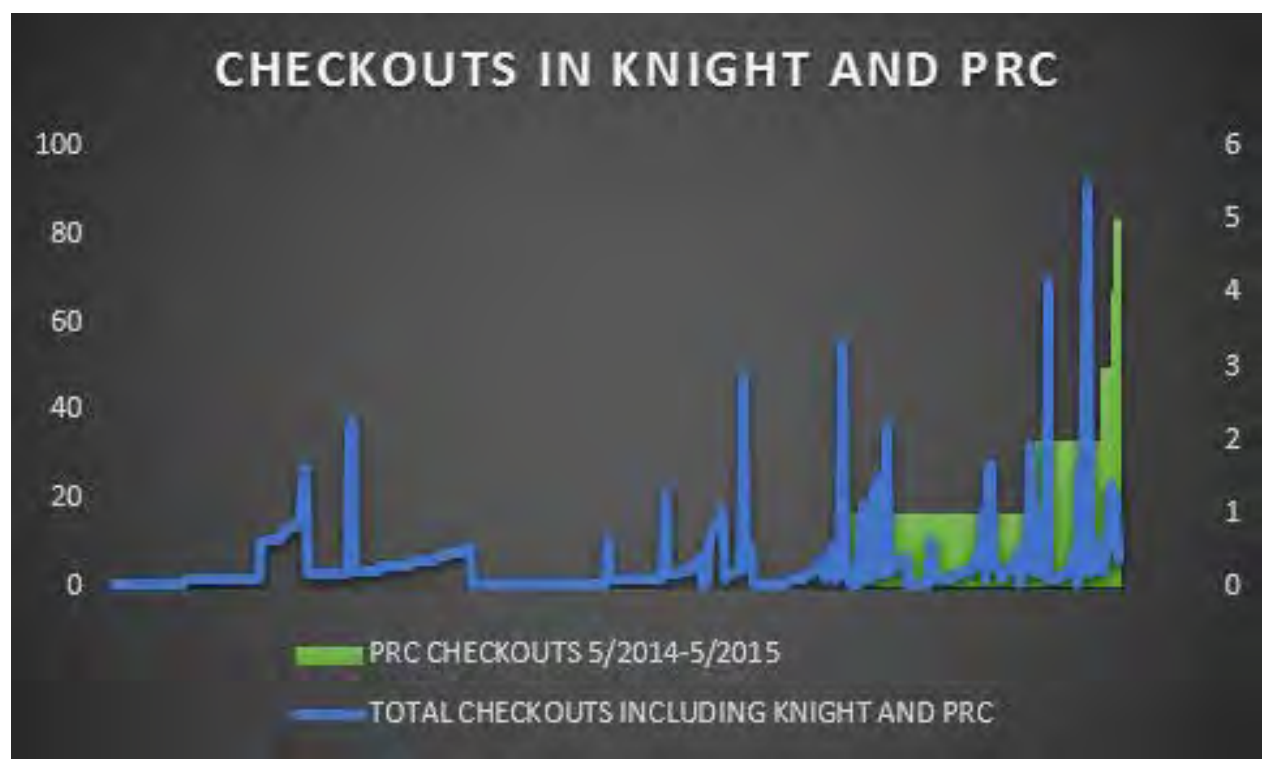

Figure 1: Total checkouts in Knight (general collection) and PRC vs. PRC alone. (Left axis " $0-100$ " corresponds with blue Total Checkouts, Right axis " $0-6$ " corresponds with green PRC Checkouts)

Generally, the older the title was the less it circulated in the PRC. The chart below shows the checkouts according to the year they were added to the collection, or more accurately, the year the bibliographic record was created in our ILS. Publication years were not available in our data set and we assume, based on historical practices, that the publication years would be the same or similar to the dates of addition to the collection. 


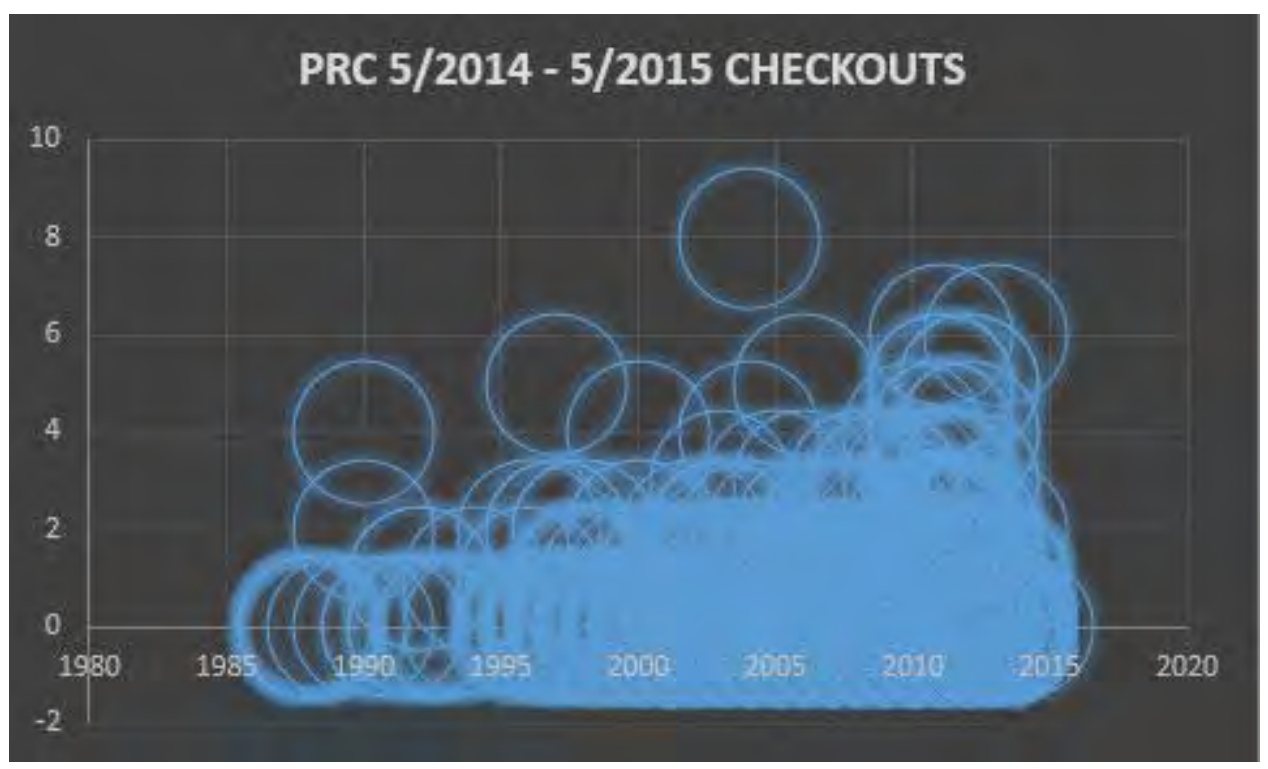

Figure 2: Each circle indicates the year an individual book was acquired (y-axis) and number of times circulated within one year ( $x$-axis).

This assessment helped us determine which materials should be moved out of the PRC back to the general collection, where we conclude our patrons expect to find older fiction, or are more likely to seek it out for specific research purposes, rather than spontaneous recreational reading.

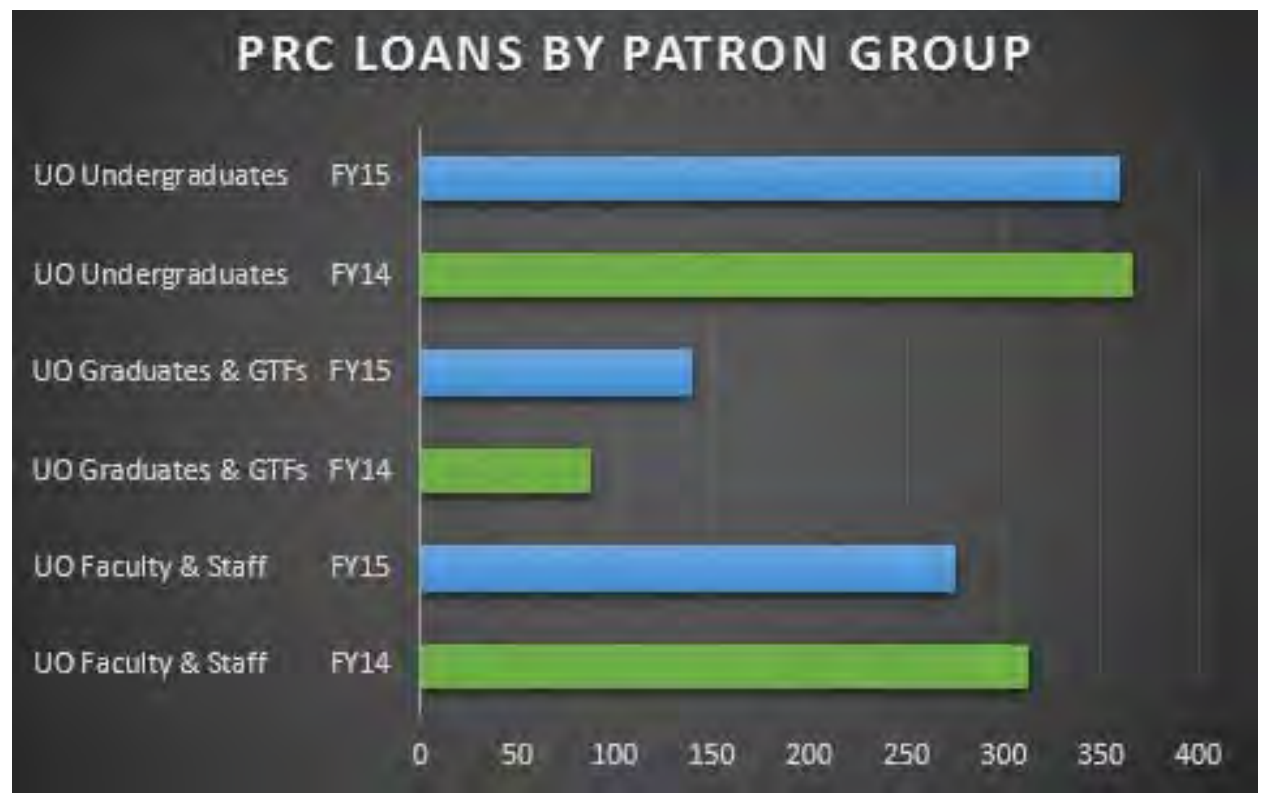

Figure 3: PRC Loans by Patron Group

"UO Undergraduates includes patron types: UO Undergraduate, UO Distance Ed Undergrad, and UO Honors Student. **UO Graduates \& GTFs includes patron types: UO Graduate, UO Graduate Teaching Fellow, and UO Law Student. ***:Patron Groups not included are incomparable between FY14 and FY15 due to the creation of new patron types. 
As we added new purchases and weeded out the older, non-circulating titles, we conducted another assessment. Total PRC circulation for FY14 was 790 of 984 McNaughton items, at a rate of 80 percent, with 510 distinct title checkouts, or 52 percent of the collection. Compare this to our homegrown collection of relocated general collection items and purchases made specifically for the PRC. In FY15 we had 844 checkouts of 770 titles, at a rate of 110 percent, with 506 of 770 distinct titles checking out, or 66 percent of the collection. A third of the 770 titles were recent additions that did not have time to circulate before the fiscal year closed. Between FY14 and FY15 total checkouts increased 6.8 percent and the checkout rate in FY15 was 37 percent higher than in FY14. Students are the most frequent users of the collection, making up 57 percent for FY14 and 59 percent of checkouts for FY15.

One additional type of use that these charts cannot capture are in-library use statistics. The UO Libraries have not been collecting reshelving statistics for this collection, but it is known from reshelving efforts that there are items being read and moved around the library daily. Items such as comic books and graphic novels, that might be considered quicker reads and therefore more conducive to in-house reading, appear to feature heavily in the reshelving pile.

While implementing and continuing to update our PRC, the UO Libraries has made gentle attempts to discourage patrons from requesting leisure reading from other libraries via Interlibrary Loan (ILL), recommending that people instead make requests for titles to be added to this local collection. We do not have any easy method for separating out ILL requests for fiction, nor for identifying leisure reading vs. fiction used for research, so we do not have statistics to demonstrate an impact in that realm. Anecdotally, however, we can speculate that the dozens of check-outs each for highly popular titles might have otherwise been attempted through ILL if we had not been providing the copies we did. For instance, since acquiring The Fault in Our Stars in September 2014, the Knight PRC copy has checked out three times to local patrons, and was sent out through Summit (the Orbis-Cascade Alliance ILL service) once, and the Law Library's PRC copy was loaned out an additional nine times to local patrons. Though these numbers may seem low relative to circulation statistics at a public library, these are phenomenal rates for books in an academic library, especially considering our lengthy loan periods.

\section{Current Iteration and Future Plans}

Our current plan for the PRC was implemented for FY15. With additional funding in FY16 the intention is to continually add new books and slowly return the general stacks books to their regular location. As of now the collection is made up of 458 books from the general collection and 312 new purchases, with dozens more in process and hundreds more on order. When the first wave of new material arrived, 300 low-circulating items from the transitional collection were returned to their original location in the general stacks in FY15. Once we acquire enough material to keep the shelves bountiful, as the books cease circulating they will be replaced with new purchases, and potentially removed from the Libraries' collections. Since the collection is meant to be ephemeral and ever-popular, the paperbacks will be recycled as they wear out.

We will continue promoting the collection to campus via bulletin boards, student groups, and other marketing tactics. Space in our library and university at large is a constant topic of discussion, and we will revisit this aspect of the initial student request as the climate allows. Our experience wielding the UO Libraries' Popular Reading Collection mirrors both 
the frenzy of the zeitgeist and ironically labyrinthine complexity of the library. The collection is nevertheless redeemed by the continued interest, the increased circulation, and congruity with other campus ventures. It has been a valuable learning experience on all fronts to develop and revise the concept and implementation of the PRC, and it has been rewarding to problem-solve and watch the fruits of our labor be harvested by eager community members. We can expect that our eager community members are also being helped in their other scholarly pursuits. In reading for leisure, they are potentially improving their reading on all fronts. For, as Neil Gaiman, a strong proponent of libraries, said in 2013, "To discover that reading per se is pleasurable. Once you learn that, you're on the road to reading everything." \&

\section{References}

Djikic, M., Oatley, K., Zoeterman, S., \& Peterson, J.B. (2009). On being moved by art: How reading fiction transforms the self. Creativity Research Journal, 21(1), 24-29. doi: http://dx.doi.org/10.1080/10400410802633392.

Elliott, J. (2007, Spring). Academic libraries and extracurricular reading promotion. Reference \& User Services Quarterly, 46(3), 34-43. http://dx.doi.org/10.5860/rusq.46n3.34.

Gaiman, N. (2013, October 15). Neil Gaiman: Why our future depends on libraries, reading and daydreaming. The Guardian. Retrieved from: http://tinyurl.com/142wz7g.

Gallik, J.D. (1999). Do they read for pleasure? Recreational reading habits of college students. Journal of Adolescent \& Adult Literacy, 42(6), 480-488.

Kelley, K.E., \& Kneipp, L.B. (2009). Reading for pleasure and creativity among college students. College Student Journal, 43(4), 1137-1144.

Kidd, D.C., \& Castano, E. (2013). Reading literary fiction improves theory of mind. Science, 342(6156), 377-380. http://dx.doi.org/10.1126/science.1239918.

UO Libraries. (2012, Aug. 21). Strategic directions, 2012-2013. Retrieved from: https://ibrary.uoregon.edu/general/about/mission.html. 